\title{
HUBUNGAN BURNOUT DAN KELUHAN NYERI MUSKULOSKELETAL PADA MAHASISWA PROFESI NERS DI UNIVERSITAS KLABAT
}

\author{
RELATIONSHIP BETWEEN BURNOUT AND MUSCULOSKELETAL PAIN \\ ON NERS STUDENT AT UNIVERSITAS KLABAT
}

\author{
James Richard Maramis ${ }^{1}$ Claudia Priscilla Kandowangko ${ }^{2}$ \\ Fakultas IImu Keperawatan, Universitas Klabat, Manado, Indonesia \\ E-mail: jmaramis@unklab.ac.id
}

\begin{abstract}
ABSTRAK
Pendahuluan: Mahasiswa keperawatan rentan mengalami keadaan lelah baik emosional, psikologi dan fisik yang dirasakan akibat melakukan aktivitas ataupun tuntutan praktik yang dilakukan secara berulang-ulang dan dalam waktu yang lama. Keluhan nyeri muskuloskeletal merupakan salah satu gejala yang terjadi pada gangguan musculoskeletal (MSDs). Tujuan: Tujuan penelitian adalah mengetahui hubungan antara burnout dan keluhan nyeri musculoskeletal pada mahasiswa profesi ners di Universitas Klabat. Metode: Metode penelitian yang digunakan ialah deskriptif correlation dengan menggunakan pendekatan cross sectional study dan pengambilan sampel dalam penelitan ini adalah menggunakan teknik purposive sampling. Pengumpulan data menggunakan kuesioner burnout dengan kuesioner Nordic Body Map yang diberikan kepada 127 mahasiswa profesi ners di Universitas Klabat dan data dianalisis dengan menggunakan uji Spearman's rho. Hasil: Didapati pada umumnya mahasiswa sebanyak 109 orang $(85,8 \%)$ memiliki tingkat burnout sedang, dan 100 mahasiswa (78,7\%) merasakan keluhan musculoskeletal ringan. Daerah tubuh yang paling banyak dikeluhkan ialah di punggung dengan jumlah nilai sebanyak 273 Sedangkan hasil uji statistic antara burnout dengan keluhan nyeri musculoskeletal menunjukkan nilai $\mathrm{p}=0,000<0,05$, dengan demikian ada hubungan antara burnout dengan keluhan nyeri musculoskeletal. Nilai $r=0,337$ yang menunjukkan arah korelasi positif antara dua variabel atau searah. Diskusi: Peneliti selanjutnya dapat meneliti pengaruh rutinitas kegiatan tertentu dan postur tubuh yang dilakukan oleh perawat ketika bekerja terhadap keluhan MSD-nya, dan juga agar mencari tahu hubungannya dengan keluhan-keluhan MSD yang dirasakan responden lebih dari tujuh hari.
\end{abstract}

Kata kunci : Burnout, keluhan nyeri musculoskeletal, Nordic Body Map

\section{ABSTRACT}

Introduction: Nursing students are prone to experience emotional, psychological and physical fatigue. This physical problem is usually felt after carrying out activities or practical demands that are carried out repeatedly and for a long time. Musculoskeletal pain complaints are one of the symptoms that occur in musculoskeletal disorders (MSDs). Purpose: The purpose of this study was to determine the relationship between burnout and complaints of musculoskeletal pain in nurses at the Klabat University. Method: The research method used is descriptive correlation using a cross sectional study approach and sampling in this research is using purposive sampling technique. Data collection used a burnout questionnaire with a Nordic Body Map questionnaire given to 127 nursing students at Klabat University and the data were analyzed using the Spearman's rho test. Results: Generally, 109 students (85.8\%) had moderate burnout levels, and 100 students (78.7\%) felt mild musculoskeletal complaints. The most complained body area is in the back with a total value of 273. While the statistical test results between burnout and musculoskeletal

JURNAL

SKOLASTIK

KEPERAWATAN

VOL. 5, NO. 2

Juli - Desember 2019

ISSN: $2443-0935$

E-ISSN 2443 - 16990 
pain complaints showed a value of $p=0,000<0.05$, thus there is a relationship between burnout and musculoskeletal pain complaints. Value $r=0.337$ which shows the direction of a positive correlation between two variables or in the same direction. Discussion: The researcher can then examine the effect of certain activities and posture routines performed by the nurse while working on her MSD complaints, and also to find out the relationship with MSD complaints felt by respondents for more than seven days.

Keywords: Burnout, musculoskeletal pain complaints, Nordic Body Map 


\section{PENDAHULUAN}

Setiap mahasiswa keperawatan yang mengikuti program Profesi Ners diberikan kesempatan untuk dapat berperan sebagai perawat professional (Nursalam, 2011). Dengan demikian, stressor yang dialami perawat yang bekerja di klinik akan sama dirasakan juga oleh mahasiswa (Devi, Hidayati, \& Nursalam, 2013).

Menurut Kasmarani (2012), perawat menanggung beban kerja yang cukup tinggi dalam melaksanakan praktek pelayanan keperawatan yang efektif. Apabila beban kerja yang berlebihan secara fisik maupun mental dilakukan terus-menerus yang akan menjadi sumber stres. Oleh sebab itu, Maharani dan Triyoga (2012) begitu pula dengan Garabrant, dkk (2019) menyatakan bahwa ketika stres kerja terjadi secara terus menerus hal tersebut dapat mengakibatkan dampak jangka panjang, yaitu mengalami masalah kesehatan fisik (misalnya: insomnia, sakit kepala, ketegangan otot) dan masalah kesehatan mental (misalnya: depresi, kecemasan, penyalahgunaan zat) termasuk juga perilaku negatif terhadap pekerjaan yang akhirnya memunculkan suatu kejenuhan kerja (burnout).

Sebagai perawat, keluhan muskuloskeletal dapat dirasakan karena adanya gerakan berulang yang dilakukan (Famawati, Tarwaka, \& Suwaji, 2016). Ditambahkan lagi oleh Anggriawan (2016), keluhan muskuloskeletal merupakan keluhan yang dapat dirasakan pada bagian-bagian otot skeletal seseorang, baik dari keluhan sangat ringan sampai pada sangat sakit.

Menurut Giang dkk (2018), dalam sektor kesehatan gangguan muskuloskeletal kerja umum terjadi dengan tingkat prevalensi Musculoskeletal diorders (MSDs) yang terkait dengan pekerjaan dilaporkan dari $28 \%$ menjadi $96 \%$ selama periode satu tahun, termasuk di kalangan perawat. Data yang ditemukan menunjukkan bahwa perawat memiliki prevalensi MSD yang sangat tinggi, misalnya di Eropa dari 10\% hingga 50\% di Prancis, 89\% di Portugal, dan $85 \%$ di Makedonial; di Amerika dari $35.1 \%$ menjadi $47 \%$ di USA dan dari $32,8 \%$ ke $57 \%$ di Brazil. Sedangkan di Asia, $78.6 \%$ di China, $85 \%$ di Arab Saudi dan di Iran 88\% (Giang dkk., 2018).

Sedangkan di Indonesia berdasarkan hasil Riset Kesehatan Dasar (2013) menunjukkan bahwa penyakit muskuloskeletal berdasarkan diagnosis oleh tenaga kesehatan, yaitu $11,9 \%$ dan berdasarkan diagnosis nakes tertinggi di Bali (19,3\%), diikuti Aceh 18,3\%), Jawa Barat $(17,5 \%)$ dan Papua (15,4\%). Di Sulawesi Utara sendiri memiliki prevalensi sebanyak $10,3 \%$.

Gangguan muskuloskeletal didefinisikan sebagai masalah kesehatan kronis dari sistem muskuloskeletal yang mengakibatkan nyeri baik di leher, bahu, pergelangan tangan, pinggul, lutut dan tumit. Faktor risiko terjadinya nyeri muskuloskeletal antara lain faktor dari individu, faktor pekerjaan atau biomekanik dan faktor psikososial (Cho, Cho, \& Han, 2016). Faktor pekerjaan merupakan faktor fisik yang meliputi postur janggal, gerakan berulang, baban, durasi kerja, temperatur rendah, getaran dan tekanan mekanik (Bush \& Nunes, 2012).

Dunn, Hammer dan Lloyd (2009) mengatakan burnout melibatkan kelelahan fisik, seperti keluhan muskuloskeletal yang timbul karena adanya gerakan berulang. Menurut Lubis (2016) burnout terjadi pada keadaan dimana seseorang di tempat kerja mengalami penurunan produktivitas karena stress di tempat kerja yang berlangsung terus-menerus. 
Banyaknya kegiatan ataupun rutinitas yang dilakukan oleh mahasiswa juga dapat menimbulkan risiko mengalami burnout (Alimah, Ekowati, \& Swasti, 2016). Balasooriya, Chunming, Harrison, Macintyre, dan Travaglia (2017) menambahkan, burnout di kalangan profesional kesehatan ditandai dengan berbagai tingkat kelelahan emosional, depersonalisasi, dan rendahnya pencapaian pribadi.

Hasil penelitian yang dilakukan oleh Ribeiro (2014) mendapati bahwa kejenuhan kerja atau (burnout) memiliki prevalensi yang sangat tinggi dalam pelayanan dan perawatan kerja, terutama dibidang kesehatan. Diperkuat lagi oleh hasil penelitian dari Brazil oleh Holmes pada tahun 2016, didapati bahwa $40 \%$ perawat mengalami kelelahan emosional, $35.4 \%$ mengalami depersonalisasi dan $40.9 \%$ mengalami penurunan pencapaian prestasi diri.

Dengan demikian, melalui studi awal yang dilakukan melalui wawancara kepada mahasiswa profesi ners didapati bahwa adanya mengenai pengeluhan kejenuhan, pengeluhan nyeri bagian musculoskeletal dalam mengerjakan tuntutan-tuntutan program Profesi Ners di Universitas Klabat, maka peneliti tertarik melakukan penelitian yang bertujuan untuk mengetahui hubungan burnout dan keluhan nyeri musculoskeletal pada mahasiswa Profesi Ners di Universitas Klabat.

\section{METODOLOGI}

Penelitian ini menggunakan desain penelitian deskriptif correlation dengan menggunakan pendekatan cross sectional, yakni objek penelitian, diukur dan dikumpulkan secara simultan, sesaat atau satu kali saja dalam satu waktu dan tidak ada follow up (Hidayat, 2009).

\section{Sampel dan Responden}

Responden dalam penelitian ini adalah semua mahasiswa Profesi Ners di Universitas Klabat.

Jumlah responden yang digunakan ialah 127 mahasiswa profesi ners. Proses pengambilan sampel dalam penelitan ini adalah menggunakan teknik purposive sampling dengan kriteria Inklusi: Mahasiswa Profesi Ners yang terdaftar aktif berkuliah pada tahun ajaran 2019/2020 semester ganjil. Kriteria eksklusi yaitu mahasiswa yang tidak hadir saat pembagian kuesioner dan tidak bersedia menjadi responden.

\section{Instrumen}

Instrumen adalah alat-alat yang digunakan untuk pengumpulan data (Nursalam, 2013). Instrument yang digunakan dalam penelitan menggunakan kuesioner burnout yang diadopsi dari Budiansya (2015) dengan hasil uji validitas cronbach alpha sebesar 0,818 dan jumlah pernyataan sebanyak 22 butir, dinilai menggunakan skala Likert dimana 1: Tidak Pernah, 2: Kadang-kadang, 3: Sering, dan 4: Selalu. Sedangkan untuk mengukur keluhan nyeri musculoskeletal menggunakan kuesioner Nordic Body Map (NBM) yang telah banyak digunakan para ahli ergonomik untuk menilai tingkat keparahan gangguan pada sistem musculoskeletal dan mempunyai validitas dan reabilitas yang cukup (Tarwaka, 2011). NBM memiliki 28 butir pernyataan dan diukur menggunakan skala Likert dimana nilai 4: sangat sakit, 3: sakit, 2: agak sakit, dan 1: tidak sakit.

\section{Pengumpulan Data}

Pengumpulan data yang dilakukan berawal dari mendapatkan izin dari institusi untuk melakukan penelitian, memilih subjek penelitian, bertemu 
dengan subjek penelitian dan penelitian dilaksanakan pada tanggal 22 November 2019 pada mahasiswa profesi ners di Universitas Klabat yang sementara melaksanakan praktek di RSJ Ratumbuysang.

Pengumpulan data dilakukan dengan cara membagikan kuesioner yang terdiri dari kuesioner burnout dan kuesioner nordic body map dalam satu kali pertemuan, lalu mendampingi responden dalam pengisian kuesioner. Setelah pengisian, maka peneliti melakukan editing data, encoding data, analisa data dan interpretasi data serta mengumpulkan hasil penelitian.

\section{HASIL}

Tabel 1. Hasil deskriptif burnout pada mahasiswa Profesi Ners di Universitas Klabat

\begin{tabular}{lllll}
\hline & & & $\begin{array}{l}\text { Valid } \\
\text { Percent }\end{array}$ & $\begin{array}{l}\text { Cumulativ } \\
\text { e Percent }\end{array}$ \\
\hline $\begin{array}{l}\text { Renda } \\
\text { h }\end{array}$ & 8 & 6.3 & 6.3 & 6.3 \\
sedang & 109 & 85.8 & 85.8 & 92.1 \\
tinggi & 10 & 7.9 & 7.9 & 100.0 \\
Total & 127 & 100.0 & 100.0 & \\
\hline
\end{tabular}

Berdasarkan tabel 1, diketahui dari 127 responden, paling banyak terdapat 109 mahasiswa $(85,8 \%)$ memiliki burnout sedang, 10 mahasiswa $(7,9 \%)$ memiliki burnout tinggi dan hanya 8 mahasiswa $(6,7 \%)$ memilliki tingkat burnout rendah. Dengan demikian, didapati bahwa mahasiswa Profesi Ners di Universitas Klabat berada dalam kategori burnout sedang.

Tabel 2. Hasil deskriptif keluhan nyeri musculoskeletal pada mahasiswa Profesi Ners di Universitas Klabat

\begin{tabular}{lllll}
\hline & Frequency & Percent & $\begin{array}{l}\text { Valid } \\
\text { Percent }\end{array}$ & $\begin{array}{l}\text { Cumulative } \\
\text { Percent }\end{array}$ \\
\hline $\begin{array}{l}\text { Tidak ada } \\
\text { keluhan }\end{array}$ & 3 & 2.4 & 2.4 & 2.4 \\
$\begin{array}{l}\text { keluhan } \\
\text { ringan }\end{array}$ & 100 & 78.7 & 78.7 & 81.1 \\
$\begin{array}{l}\text { keluhan } \\
\text { sedang }\end{array}$ & 22 & 17.3 & 17.3 & 98.4 \\
$\begin{array}{l}\text { keluhan } \\
\text { tinggi }\end{array}$ & 2 & 1.6 & 1.6 & 100.0 \\
Total & 127 & 100.0 & 100.0 & \\
\hline
\end{tabular}

Berdasarkan tabel 2, didapati hasil bahwa kebanyakan mahasiswa memiliki keluhan musculoskeletal ringan, yaitu sebanyak 100 mahasiswa $(78,7 \%)$, kemudian 22 mahasiswa $(17,3 \%)$ mengeluh sedang, dan 3 mahasiswa $(2,4 \%)$ tidak memiliki keluhan, sedangkan yang paling sedikit memiliki keluhan tinggi sebanyak 2 mahasiswa $(1,6 \%)$.

Tabel 3. Hasil analisis lokasi keluhan nyeri musculoskeletal pada mahasiswa profesi ners di Universitas Klabat

\begin{tabular}{ll}
\hline Lokasi Nyeri & Scoring \\
\hline Punggung & 273 \\
Betis kiri & 255 \\
Betis kanan & 254 \\
Pinggang & 251 \\
Bahu kanan & 248 \\
Bahu kiri & 247 \\
Kaki kiri & 236 \\
Kaki kanan & 234 \\
Leher atas & 233 \\
Leher bawah & 227 \\
Lengan atas kanan & 222 \\
Pergelangan kaki kanan & 216 \\
Lengan atas kiri & 215 \\
Pergelangan kaki kiri & 209 \\
Pantat (Buttock) & 207 \\
Tangan kanan & 205 \\
Pergelangan tangan kanan & 202 \\
Paha kanan & 200
\end{tabular}




\begin{tabular}{ll} 
Lutut kanan & 194 \\
Paha kiri & 192 \\
Pergelangan tangan kiri & 187 \\
Pantat (Bottom) & 186 \\
Tangan kiri & 186 \\
Lutut kiri & 184 \\
Lengan bawah kiri & 183 \\
Lengan bawah kanan & 181 \\
Siku kanan & 170 \\
Siku kiri & 162 \\
\hline
\end{tabular}

Berdasarkan tabel 3, didapati lokasi yang paling banyak dikeluhkan oleh mahasiswa pertama ialah di daerah punggung (273), kemudian betis kiri (255) dan kanan (254), diikuti oleh lokasi lainnya.

Tabel 4. Hasil uji hubungan burnout dengan keluhan nyeri musculoskeletal pada mahasiswa Profesi Ners di Universitas Klabat

\begin{tabular}{|c|c|c|c|}
\hline & \multicolumn{3}{|c|}{ kategori } \\
\hline & & burnout & $\begin{array}{l}\text { kategori_ } \\
\text { nbm }\end{array}$ \\
\hline \multirow[t]{3}{*}{$\begin{array}{l}\text { Spear kategor } \\
\text { man' i_burno } \\
\text { s rho ut }\end{array}$} & $\begin{array}{l}\text { Correlati } \\
\text { on } \\
\text { Coefficie } \\
\text { nt }\end{array}$ & 1.000 & $.337^{* *}$ \\
\hline & $\begin{array}{l}\text { Sig. (2- } \\
\text { tailed) }\end{array}$ & & .000 \\
\hline & $\mathrm{N}$ & 127 & 127 \\
\hline
\end{tabular}

Hasil yang didapati berdasarkan tabel 3, nilai $\mathrm{p}=0,000$ dimana nilai signifikan $\alpha=\leq 0,05$ yang berarti menunjukkan adanya hubungan yang signifikan antara burnout dengan keluhan nyeri musculoskeletal. Didapati hasil nilai $\mathrm{r}=0,337$ yang berarti terdapat hubungan yang searah, yaitu menunjukkan semakin tinggi burnout yang dikeluhkan oleh mahasiswa profesi ners, maka semakin tinggi pula keluhan nyeri musculoskeletal pada mahasiwa profesi ners di Universitas
Klabat dan antara burnout dengan keluhan nyeri musculoskeletal memilki kekuatan hubungan yang lemah.

\section{Temuan Hasil Dan Pembahasan}

Hasil deskriptif tingkat burnout menunjukkan sebagian besar mahasiswa Profesi Ners di Universitas Klabat berada pada tingkat burnout sedang, sebanyak 109 mahasiswa $(85,8 \%)$. Hasil penelitian ini sama dengan yang didapatkan oleh Alimah, Ekowati, dan Swasti (2016) dalam penelitiannya dari 156 responden didapati mahasiswa mengalami burnout tingkat sedang (56.4\%).

Berdasarkan hasil wawancara dalam pengisian kuesioner, keluhan yang sering dirasakan mahasiswa ialah merasa adanya semangat yang berkurang, adanya masalah makan dan tidur ketika memikirkan tentang tugas, dan merasa kurang dalam memberikan asuhan keperawatan secara holistik.

Liliweri (2017) mengatakan bahwa burnout merupakan suatu kondisi psikologis pada seseorang yang tidak berhasil mengatasi stres kerja sehingga menyebabkan stres berkepanjangan dan mengakibatkan gejala-gejala seperti kelelahan emosional, kelelahan fisik, kelelahan mental, dan rendahnya penghargaan terhadap diri sendiri.

Hasil uji frekuensi dan persentase keluhan nyeri musculoskeletal didapati bahwa mahasiswa Profesi Ners di Universitas Klabat memiliki keluhan ringan, sebanyak 100 orang $(78,7 \%)$.

Berdasarkan hasil wawancara dan pengisian kuesioner pada mahasiswa didapati keluhan nyeri muskuloskeletal ringan karena pengambilan data dilakukan di saat mahasiswa sedang praktik di RSJ Ratumbuysang dan kebanyakan beban kerja yang dilakukan hanya melakukan 
interaksi dengan pasien tanpa melakukan banyak tindakan lainnya.

Badley, Perruccio, Power, dan Yip (2017) berpendapat bahwa musculoskeletal disorders (MSDs) meliputi sekelompok gangguan yang berhubungan secara anatomis dan berhubungan dengan keterbatasan fungsi fisik dan nyeri. Faktor risiko terjadinya nyeri muskuloskeletal antara lain faktor dari individu, faktor psikososial dan faktor pekerjaan atau biomekanik (Cho, Cho, \& Han, 2016). Bush dan Nunes (2012) mengutarakan bahwa faktor pekerjaan merupakan faktor fisik yang meliputi postur janggal, gerakan berulang, baban, durasi kerja, temperatur rendah, getaran dan tekanan mekanik.

Didapati hasil keluhan lokasi nyeri muskuloskeletal terbanyak ialah pada daerah punggung dengan nilai sebanyak 273. Sejalan dengan penelitian yang dilakukan oleh Artha, Kurniawan, Prawira, dan Yanti (2017) pada 72 mahasiswa didapati kebanyakan mengeluh pada bagian punggung $(59,73 \%)$.

Alasan yang diberikan oleh mahasiswa melalui wawancara saat pengisian kuesioner mengapa daerah punggung masih terasa sakit ialah karena cara duduk saat mengerjakan tugas tidak selalu tegak atau lebih tepatnya membungkuk, sehingga dapat membebani punggung. Tugas yang dibuat pun sering lebih dari satu jam dengan posisi duduk tanpa adanya sandaran di daerah punggung.

Hasil uji analisa hubungan antara burnout dengan keluhan nyeri musculoskeletal pada mahasiswa di Universitas Klabat, mendapati nilai $\mathrm{p}=0,000<0,05$, hal ini menunjukkan bahwa ada hubungan yang signifikan antara burnout dengan keluhan nyeri musculoskeletal. Sejalan dengan penelitian sebelumnya yang dilakukan oleh Aasland, Falkum, Hagtvet, Innstrand, dan Langballe (2009) yang dilakukan pada 4507 responden didapati hasil bahwa ada hubungan yang signifikan dan positif antara burnout dan keluhan nyeri musculoskeletal pada semua kelompok pekerjaan.

Maharani \& Triyoga (2012), dan juga Garabrant dkk (2019) memperjelas bahwa ketika stres kerja terjadi secara terus menerus hal tersebut dapat mengakibatkan dampak jangka panjang, yaitu mengalami masalah kesehatan fisik (misalnya: insomnia, sakit kepala, ketegangan otot).

\section{Keterbatasan Studi}

Pelaksanaan penelitian ini memiliki keterbatasan waktu untuk pengisian kuesioner keluhan nyeri musculoskeletal hanya dilakukan selama tujuh hari. Keterbatasan lain adalah pada saat pengambilan data, mahasiswa telah melewati masa praktik dengan beban kerja yang cukup tinggi, dimana tempat pengambilan data dilakukan saat mahasiswa sementara praktik kinis di RSJ Ratumbuysang, dan tuntutan kerja mahasiswa kebanyakan hanya melakukan interaksi dengan pasien di tempat.

\section{Implikasi Studi}

Dari hasil penelitian ini diharapkan dapat menambah informasi mengenai adanya hubungan antara burnout dengan keluhan nyeri musculoskeletal pada mahasiswa profesi ners dan dapat menjadi acuan motivasi bagi mahasiswa untuk dapat mengurangi tingkat burnout dan keluhan nyeri musculoskeletal.

\section{KESIMPULAN}

Kesimpulan yang dapat diambil berdasarkan hasil uji analisa data tentang burnout dengan keluhan nyeri musculoskeletal pada mahasiswa Profesi Ners di Universitas Klabat, ialah: 
1. Dari 127 responden didapati paling banyak 109 mahasiswa $(85,8 \%)$ memiliki burnout sedang, 10 mahasiswa $(7,9 \%)$ memiliki burnout tinggi dan hanya 8 mahasiswa $(6,7 \%)$ memilliki tingkat burnout rendah. Dengan demikian, didapati bahwa mahasiswa Profesi Ners di Universitas Klabat berada dalam kategori burnout sedang

2. Dari 127 responden didapati hasil bahwa kebanyakan mahasiswa memiliki keluhan musculoskeletal ringan, yaitu sebanyak 100 mahasiswa $(78,7 \%)$, kemudian 22 mahasiswa $(17,3 \%)$ mengeluh sedang, dan 3 mahasiswa $(2,4 \%)$ tidak memiliki keluhan, sedangkan yang paling sedikit memiliki keluhan tinggi sebanyak 2 mahasiswa $(1,6 \%)$.

3. Dari 127 responden, keluhan nyeri tertinggi pada daerah punggung (273), kemudian betis kiri (255) dan kanan (254), diikuti oleh daerah lainnya.

4. Hasil analisis uji statistic yang didapati nilai $\mathrm{p}=0,000<0,05$, yang berarti ada hubungan yang signifikan antara burnout dengan keluhan nyeri musculoskeletal pada mahasiswa Profesi Ners di Universitas Klabat.

\section{REKOMENDASI}

Meneliti pengaruh rutinitas kegiatan dan postur tubuh yang dilakukan oleh perawat ketika bekerja terhadap keluhan MSDnya, dan juga agar mencari tahu hubungannya dengan keluhan-keluhan MSD yang dirasakan responden lebih dari tujuh hari.

Hasil dari penelitian ini dapat digunakan sebagai bahan pembelajaran mahasiswa keperawatan sehingga saat mahasiswa memberikan tindakan keperawatan dapat dilakukan pencegahan keluhan untuk mengurangi tingkat keluhan nyeri ataupun burnout.

Dapat memanfaatkan sumberdaya yang tersedia di kampus Universitas Klabat dan Fakultas Keperawatan dalam mengatasi burnout dengan keluhan nyeri musculoskeletal yang dirasakan.

\section{DAFTAR PUSTAKA}

Aasland, O., Falkum, E., Hagtvet, K., Innstrand, S., \& Langballe, E. (2009). The relationship between burnout and musculoskeletal pain in seven Norwegian occupational groups. Work 32, 179-188.

Alimah, Ekowati, \& Swasti. (2016). Gambaran burnout pada mahasiswa keperawatan di purwokerto. Jurnal Keperawatan Soedirman (The Soedirman Journal of Nursing), Volume 11, No. 2, 130-141.

Anggriawan. (2016). Pengaruh pemberian peregangan otot (stretching) terhadap keluhan muskuloskeletal dan kejenuhan pada pekerja bagian menjagi divisi garment di PT. Tyfountex Indonesia Sukoharho. Sukaharjo: Universitas Muhammadiyah Surakarta.

Artha, P., Kurniawan, E., Prawira, M., \& Yanti, N. (2017). Faktor yang berhubungan terhadap keluhan muskuloskeletal pada mahasiswa Universitas Udayana tahun 2016. Journal of Industrial Hygiene and Occupational Health, Volume 1 No. 2, 102-118. 
Badley, Perruccio, Power, \& Yip. (2017). Musculoskeletal disorders: a neglected group at public health and epidemiology meetings? American $J$ Public Health, 107(10), 1584-1585.

Balasooriya, Chunming, Harrison, Macintyre, \& Travaglia. (2017). Burnout in medical students: a systematic review of experiences in Chinese medical schools. Chunming et al. BMC Medical Education (17), 1-11.

Budiansya, T. (2015). Hubungan gaya kepemimpinan kepala ruangan dengan burnout perawat pelaksana di ruang rawat inap Rumah Sakit Dr. Pirngadi Medan. Skripsi: Universitas Sumatra Utara.

Bush, \& Nunes. (2012). Work-related musculoskeletal disorders assessment and prevention. London: Intechopen.

Cho, K., Cho, H., \& Han. (2016). Risk factors associated with musculoskeletal symptoms in Korean dental practitioners. $J$. Phys. Ther. Sci. 28, 56-62.

Devi, Hidayati, \& Nursalam. (2013). Burnout syndrom mahasiswa profesi ners berdasarkan analisis faktor stressor, relational, meaning dan coping strategy. Jurnal Ners. Vol 8, No.2, 175182.

Dunn, Hammer, \& Lloyd. (2009). Psychology applied to modern life
- USA: Wadsworth Cengange Learning.

Famawati, Tarwaka, \& Suwaji. (2016). Hubungan risiko patient handling dengan keluhan muskuloskeletal pada perawat bagian IGD RSUD DR Moewardi di Surakarta. Surakarta: Universitas Muhammadiyah Surakarta

Garabrant, Henry, Miller, Rollins, Salyers, Shimp, et al. (2019). The impact of burnout on patient centerd care: a comparative effectiveness trial in mental health. Indiana: ACT Center of Indiana.

Giang, Hai, Hong, Khue, Luan, Thuc, et al. (2018). Musculoskeletal disorders: prevalence and associated factors among district hospital nurses in Haiphong, Vietnam. BioMed Research International, Volume 2018, 1-9.

Hatati, \& Ratnasari. (2019). Manajemen kinerja dalam organisasi. Qiara Media.

Hidayat, A. (2009). Metode Penelitian keperawatan dan teknik penetapan sampel. Jakarta: Salemba Medika.

Huang, X., Chang, J., Sun, F., \& Ma, W. (2010). Nursing students' experiences of their first encounter with death during clinical practice in Taiwan. Journal of Clinical Nursing, 19(15-16), 2280-2290. doi:10.1111/j.1365-2702.2009. 03090.x. 
Kasmarani. (2012). Pengaruh beban kerja fisik dan mental terhadap stress kerja pada perawat di Instalasi Gawat Darurat (IGD) RSUP Cianjur. Jurnal Kesehatan Masyarakat, I(02), 1-2.

Liliweri, A. (2017). Komunikasi antar personal. Jakarta: Kencana.

Lubis, N. (2016). Depresi tinjauan psikologis. Jakarta: KENCANA.

Maharani, \& Triyoga. (2012). Kejenuhan kerja (burnout) dengan kinerja perawat dalam pemberian asuhan keperawatan. Jurnal STIKES, Volume 5, No. 2, 167-178.

Marcysiak, M., Dąbrowska, O., \& Marcysiak, M. (2013). Acceptance of death as a life attitude for nurses and nursing students. Prog Health Sci, Vol 3, Nol Acceptance of death as an attitude, 104-110.

Martiana, \& Nuryaningtyas. (2014). Analisis tingkat risiko muskuloskeletal disorders (MSDs) dengan the rapid upper limbs assessment (RULA) dan karakteristik individu terhadap keluahan MSDs. The Indonesian Journal of Occupational SAfety Health, Vol. 2, No. 2, 160-169.

Mumbrue, T. (2010). The lived experience of nurses who encounter the unexpected death of a patient. A clinical paper submitted in partial fulfillment of the requirements for the degree of Master of Science in nursing family nurse practitioner at The university of wisconsin. WI 54901-8621.

Niederitter, J. (2009). Student Nurses' Perception of Death and Dying.

Nursalam. (2011). Manajemen keperawatan aplikasi dalam praktik keperawatan profesional. Edisi 3. Jakarta: Salemba Medika.

Nursalam. (2013). Metodologi penelitian ilmu keperawatan: pendekatan praktis. Jakarta: Salemba Medika.

Tarwaka. (2011). Ergonomi industri, dasar-dasar pengetahuan ergonomi dan aplikasi di tempat kerja. Solo: Harapan Press Solo.

Tiwaken, S., Caranto, L., \& David, J. (2015). The real world: lived experiences of student nurses during clinical practice. International Journal of Nursing Science, $\mathrm{p}$ 66-75.

White, K., Coyne, P., \& Pattel, U. (2001). Are nurses adequately prepared for end-of-life care? J Nurs Scholarsh $33(2), 147$ 